\title{
An Exploration of Faculty Experiences With Open Access Journal Publishing at Two Canadian Comprehensive Universities
}

\author{
Barbara McDonald \\ McLaughlin Library \\ University of Guelph \\ barbara.mcdonald@uoguelph.ca \\ (Brock University 2010 to 2015) \\ Ian Gibson \\ James A. Gibson Library \\ Brock University \\ igibson@brocku.ca \\ Elizabeth Yates \\ James A. Gibson Library \\ Brock University \\ eyates@brocku.ca
}

Carol Stephenson

Council of Prairie and Pacific University Libraries

carol@coppul.ca

(Wilfrid Laurier University 2006 to 2016)

\begin{abstract}
Introduction: This exploratory study was intended to shed light on Canadian academics' participation in, knowledge of and attitudes towards Open Access (OA) journal publishing. The primary aim of the study was to inform the authors' schools' educational and outreach efforts to faculty regarding OA publishing. The survey was conducted at two Canadian comprehensive universities: Brock University (St. Catharines, Ontario) and Wilfrid Laurier University (Waterloo, Ontario) in 2014. Methods: A web-based survey was distributed to faculty at each university. The data was analyzed using descriptive statistics. Limitations: Despite the excellent response rates, the results are not generalizable beyond these two institutions. Results: The Brock response rate was $38 \%$; the Laurier response rate was $23 \%$ from full-time faculty and five percent from part-time faculty. Brock and Laurier faculty members share common characteristics in both their publishing practices and attitudes towards OA. Science/health science researchers were the most positive about OA journal publishing; arts and humanities and social sciences respondents were more mixed in their
\end{abstract}


perceptions; business participants were the least positive. Their concerns focused on OA journal quality and associated costs. Conclusion: While most survey respondents agreed that publicly available research is generally a good thing, this study has clearly identified obstacles that prevent faculty's positive attitudes towards OA from translating into open publishing practices.

\section{Keywords}

Scholarly communications; Open Access; scholarly publishing; journals; faculty; gold $\mathrm{OA}$

\section{Introduction}

Despite the growing dissemination possibilities presented by technology over the past two decades, scholarly publishing has not been radically transformed. From the point of view of authors, what has evolved is a complex and confusing scholarly publishing environment when trying to decide where to publish.

The past decade has seen a proliferation of new OA journals. The Directory of Open Access Journals (DOAJ) grew from 2,514 journals in 2006 to 10,963 at the end of 2015 (Morrison, 2015). Many of these journals are now receiving the traditional marks of respectability, such as the 1,200 OA titles with an impact factor designation in Thomson Reuters' Journal Citation Reports or the many OA titles that are now included in major abstracting services. For example, Scopus indexes more than 4,000 OA titles (Steiginga \& Evans, 2015).

This increase in OA journals has been accompanied by conflicting voices, proclamations, and perceptions about OA publishing, creating an atmosphere of uncertainty and confusion for authors. Government policies calling for open dissemination of publicly funded research (Open Science Initiative Working Group, 2015) coexist with concerns about "predatory" OA publishers (Beall, 2014). Concerns about $O A$ are exacerbated by the perception that all OA journals impose article processing charges (APCs) (Beall, 2015). The reality is that OA is "...like the Wild West; some OA journals are great, while others are fly-by-night" (Dowdy, Crotty, Bernhardt, Smith \& Mayo, 2014, p. 190).

In defining OA for the purposes of the survey, the authors excluded "green" OA (wherein a version of an article is deposited in a subject or institutional repository) and "hybrid" OA (wherein selected articles from a single issue may be made OA). The decision to focus on "gold" OA journals was made, since much of the controversy shaping faculty's publishing behaviours-such as concerns about APCs and the fear of predatory publishers-is centred on OA journals. In addition, many Canadian universities have a financial stake in gold OA through their open access author funds, which cover the costs of APCs for institutional researchers (CARL Open Access Working Group, 2016). 
The definition provided to survey participants was based on Suber (2004):

A journal which makes all of its content immediately available for free to its readers. Readers do not pay any subscriptions or other fees to access any articles in an Open Access journal. In today's information ecosystem, open access (or $\mathrm{OA}$ ) journals co-exist with traditional, subscription-based scholarly journals.

\section{Canadian Context}

Canada's major public funding agencies-the Social Sciences and Humanities Research Council (SSHRC), Canadian Institutes of Health Research (CIHR), and the Natural Sciences and Engineering Research Council of Canada (NSERC), collectively known as the Tri-Council or Tri-Agency-only recently adopted OA. Though SSHRC "took the position of supporting open access in principle" in 2004, prior to 2015 only CIHR actually had a mandate requiring publicly funded research to be made publicly accessible (SSHRC, 2004). Initial consultations around a new Tri-Agency policy on Open Access in late 2013 were the impetus behind the research presented here. The Tri-Agency Open Access Policy on Publications, released in February 2015-by which time our study had been completed-was met with vocal concern during the consultation phase. Canadian scholars and journal editors/publishers expressed worries regarding the effects $\mathrm{OA}$ journal publishing in general-and the Policy in particularwould have on Canadian scholarly publishers. There were fears that the Policy would "undermine scholarly publishing in Canada" (NSERC, 2014, p. 6). A 2011 report by the Canadian Association of Learned Journals cautioned that Canadian scholarly publishing, already at risk due to lack of ongoing funding, faced further threats from the emerging OA business model (2011, p. 23). In finalizing the Policy, the Tri-Agency was challenged with balancing the public policy OA imperative with calls to ensure that the government-and the new Policy-would guarantee sufficient ongoing funding for Canadian scholarly publishers (Canadian Association of Learned Journals, 2015).

\section{Local Context}

The new Canadian Policy heightens the need for librarians to understand researcher practices, behaviours, and attitudes in order to support them effectively. As librarians, the authors were keen to understand how faculty at their institutions were dealing with and thinking about $O A$ journal publishing. Better understanding faculty's experiences would help to tailor scholarly publishing support programs and outreach efforts to university stakeholders.

This exploratory study was intended to shed light on Canadian academics' participation in, knowledge of and attitudes towards OA journal publishing. The primary aim of the study was to inform the educational and outreach efforts to faculty regarding $O A$ publishing at two medium-sized Canadian comprehensive universities: Brock University in St. Catharines, Ontario and Wilfrid Laurier University in Waterloo, Ontario. 


\section{Literature Review}

In the Canadian and international literature reviewed, surveys and interviews were found to be the predominant methodologies employed by researchers seeking to understand OA author practices. There is strong evidence that "authors' understanding and practices concerning OA have changed over time" (Togia \& Korobili, 2014, p.229; Xia, 2010), although some, such as Kleinman (2011), have expressed frustration at the lack of theoretical grounding and "disregard for basic statistical principles" in many OA research studies (p. 19). However, Kleinman also recognizes "the study of open access practices among research faculty is quite new, and methodologies and conceptual frameworks for understanding them are still under development" (p. 4).

Canadian studies at the University of Toronto, University of Saskatchewan, and York University found that faculty had considerable awareness of OA (Moore, 2011; Dawson, 2014; Nariani \& Fernandez, 2012). Moore (2011) and Dawson (2014) furthermore noted a high degree of support for the principle of OA among their respective respondents. However, the studies reviewed also demonstrated a wide range of faculty participation in OA journal publishing, from a low of $33 \%$ to a high of $71 \%$ (Fowler, 2011, Table 7; Wiley, 2012; Dallmeier-Tiessen et al., 2011). In some cases, academic discipline may also play a role: in one major Canadian study conducted by Phase 5 Consulting on behalf of the not-for-profit scholarly publisher Canadian Science Publishing, researchers from the fields of biology and the life sciences were more likely than any other discipline to report having published in an OA or hybrid journal (55\%).

Xia's (2010) meta-analysis of literature published between 1991 and 2008 found that while academics increased their awareness of, and participation in OA, concerns about quality, reputation, and a perceived lack of peer review remained constant. Togia and Korobili's (2014) meta-synthesis of 15 articles published between 2002 and 2013 reveals that "although academic researchers are aware of the fact that OA journals can bring many advantages in research visibility and impact, OA publishing is not yet fully understood; neither has it reached its full potential", highlighting the issues of quality, reputation, and impact of OA journals as significant researcher concerns (p. 229).

The 2010 Study of Open Access Publishing (SOAP) surveyed researchers in 162 countries and reported "an overwhelming support for the idea of open access, while highlighting funding and (perceived) quality as the main barriers to publishing in open access journals" (Dallmeier-Tiessen et al., 2011). Publisher Taylor \& Francis ran two large-scale OA surveys, publishing results in 2013 and 2014. In the 2014 report, 35\% of respondents agreed or strongly agreed that $O A$ journals were of lower quality than subscription-based journals, showing little change from 34\% in 2013 (Frass, Cross \& Gardner, 2014. p. 7). In May 2012, Wiley conducted a survey of its authors; of the 10,000 authors who responded, one third indicated having published in an OA journal. Participants also expressed concerns about the lack of prestige ("profile"), funding, and quality barriers (Wiley, 2012). 
Despite the above-mentioned apprehensions, the authors nonetheless noted the widespread perception that, in principle, OA journal publishing is good for research dissemination. Eighty-nine percent of SOAP respondents "considered open access publishing beneficial for their research field", with some disciplinary variations: $90 \%$ in most of the social sciences and humanities; $80 \%$ in the fields of chemistry, astronomy, physics, and engineering (Dallmeier-Tiessen et al., 2011, p. 87). The Phase 5 Research Study (2014) found that while researchers were positive about OA in principle (83\%), there was a disconnect between their beliefs that OA is good and their actual practices. Fewer than half had published in an OA or hybrid journal in the past two years and "the availability of open access as a publishing option was not an important decision criterion when selecting a journal in which to publish." (p. 5). The SOAP study also revealed an incongruence between positive views of $O A$ and the number of articles published via OA: approximately $8 \%$ of articles published by respondents were published in OA journals in 2008 (Dallmeier-Tiessen et al., 2011).

The quality of $O A$ journals emerges as a theme in many studies (Dallmeier-Tiessen et al., 2011; Fowler, 2011; Moore, 2011; Reinsfelder, 2012; Wiley, 2012; Xia, 2010). A 2014 Taylor and Francis study found that "researchers are positive but some uncertainty still remains" (Frass, Cross \& Gardner, 2014, n.p.). The study revealed mixed perceptions about quality, with responses split almost evenly between those who perceived OA journals being of lower quality, those who had no opinion ("neutral"), and those who perceived OA journals as being of higher quality than subscription journals. Concern and confusion about APCs also permeate researchers' responses in a variety of studies (Fowler, 2011; Moore, 2011; Togia \& Korobili, 2014). As noted in the introduction, many players in the scholarly publishing world conflate OA journals with APCs, leading researchers to assume that all OA journals charge APCs. Studies report substantial resistance to paying the APC's required by some OA journals, either because researchers are unable to pay or are unwilling to do so. In Fowler's 2010 study, which involved more than 600 mathematicians worldwide, respondents expressed "substantial philosophical opposition to OA journal models that charge author fees" (para. 1). Forty-three percent of Canadian science researchers agreed that the "financial cost of open access is not worth the argued benefits" while only $22 \%$ agreed that publishing in OA or hybrid journals is affordable. (Phase 5 Consulting, 2014, p.28). Just over one third of NSERC recipients and one fifth of CIHR recipients did not know whether Canadian granting agencies even support researchers in publishing open access (Phase 5 Consulting, 2014, p. 6). In summary, while faculty participation in OA journal publishing appears to be growing, they continue to express significant concerns and confusion about this emerging scholarly publishing model.

\section{Methodology}

\section{Data Collection}

A survey instrument (Appendix A), partly based on a questionnaire created by Dawson (2014), was developed to explore three questions:

1. Do faculty participate in OA journal publishing? 
2. What do faculty know about $O A$ journals?

3. What are their general attitudes toward OA journals?

The survey was presented to participants in four sections:

- Part 1: Publishing Practices (questions 1-3)

- Part 2: Knowledge of OA Journal Publishing (questions 4-7)

- Part 3: Attitudes Toward OA (questions 8-10)

- Part 4: Demographics (questions 11-14)

In addition, participants were invited to submit comments on questions 2, 3, 5, 7, 8, 9 and any "final comments" in question 10.

Ethics clearance for this study was obtained from Brock University (SREB \#13-153) and Wilfrid Laurier University (Ethics \#4212).

The online survey was created using the Fluid Surveys tool and was deployed for approximately a month at Brock University in March and April of 2014 and in October and November of 2014 at Wilfrid Laurier University. At Brock University, personalized survey invitations were emailed to 547 Brock faculty members in all departments and to all ranks (Assistant Professor, Associate Professor, Full Professor, Limited Term Appointment, Emeritus). At Laurier University, survey invitations were distributed via email listservs to full-time and part-time faculty. Participants were guaranteed anonymity and were able to exit the 10-minute survey at any time. Incomplete survey responses were discarded. No incentives were provided to participate in the survey.

\section{Data Analysis}

Data was analyzed using descriptive statistics. The anonymized raw data is available online at the Scholars Portal Dataverse Network: http://hdl.handle.net/10864/11168. Responses were downloaded into Excel spreadsheets and analyzed with the use of pivot tables and comment coding. To facilitate comparison across both institutions, disciplines were assigned to one of five broad categories: arts and humanities, business, health science/science, social sciences, and unknown.

The survey generated substantial textual responses: 116 Brock respondents and 67 Laurier respondents provided comments. Comments on questions 2, 3, 5, 7, 8, 9 and 10 (See Appendix A for survey questions) were gathered, analyzed, and categorized per the broad survey questions (participation in OA journal publishing; knowledge about OA journal publishing; attitudes towards OA journal publishing - negative, neutral, or positive).

\section{Limitations}

Despite the excellent response rates, the results are not generalizable beyond these two institutions.

Hindsight reveals the need to thoroughly revamp the survey instrument for future iterations, including: reducing the overall number of questions, moving some questions 
to different sections of the survey, and using more precise language (i.e.: OA Publishing vs. OA Journal Publishing). In addition, Question 2 (factors influencing decisions on where to publish) should be revised to include an option for "fit" (journal selection based on reaching a specific target audience) and to allow respondents to indicate that many of the listed factors are interrelated. Moreover, an error in the survey at Laurier allowed participants to pick more than four factors in Question 2 and to rate more than one factor as "most important". Finally, offering the option of comments for Question 6 would have been helpful to clarify some confusing responses.

\section{Results}

At Brock, 208 surveys were completed for a response rate of $38 \%$, while a total 138 respondents completed the survey at Laurier, with a response rate of approximately $23 \%$ from full-time faculty and five percent from part-time faculty. Because participants were not required to answer every question, less than a 100\% response rate was recorded on some questions.

\section{Part 1. Publishing Practices}

Brock and Laurier faculty share common characteristics in their publishing practices.

Question 1: How many articles have you published as primary author in scholarly journals over the span of your academic career?

\begin{tabular}{|l|r|r|r|r|}
\hline Table 1 \\
\# Articles Published as Primary Author During Academic Career (Q1) \\
\hline \multicolumn{2}{|c|}{ Brock } & \multicolumn{2}{c|}{ Laurier } \\
\hline \multicolumn{1}{|c|}{ \# articles } & $\mathrm{n}=206$ & $\%$ & $\mathrm{n}=137$ & $\%$ \\
\hline $0-9$ & 78 & $37 \%$ & 58 & $42 \%$ \\
\hline $10-19$ & 61 & $29 \%$ & 36 & $26 \%$ \\
\hline $20-29$ & 27 & $13 \%$ & 10 & $7 \%$ \\
\hline $30+$ & 46 & $22 \%$ & 33 & $24 \%$ \\
\hline
\end{tabular}

\section{Question 2: What factors influence your decisions on where to publish? Please select the four factors most important to you and rank in order of importance from 1 (most important) to 4 (least important)}

An error in the survey at Laurier allowed participants to pick more than four responses and to rate more than one factor as most important. For the purposes of this analysis, surveys that contained more than four answers to this question were excluded.

Participants at both schools identified the same top three factors: peer review, prestige, and Impact Factor (see Table 2). 


\begin{tabular}{|l|l|l|}
\hline \multicolumn{2}{|l|}{ Table 2} \\
Most Important Factors Influencing Decision on Where to Publish (Q2) \\
\hline Publication Factor & Brock ( $\mathrm{n}=204)$ & Laurier ( $\mathrm{n}=80)$ \\
\hline Journal is peer reviewed & $44 \%$ & $51 \%$ \\
\hline Journal prestige within my discipline & $29 \%$ & $33 \%$ \\
\hline Impact factor (IF) & $14 \%$ & $8 \%$ \\
\hline Quality of editor / editorial board & $6 \%$ & $3 \%$ \\
\hline Impact on my promotion / tenure process & $2 \%$ & $5 \%$ \\
\hline $\begin{array}{l}\text { My work is more likely to be cited if published } \\
\text { here }\end{array}$ & $2 \%$ & $0 \%$ \\
\hline $\begin{array}{l}\text { Articles in the journal are available to the } \\
\text { general public }\end{array}$ & $2 \%$ & $0 \%$ \\
\hline Speed of review process & $1 \%$ & $1 \%$ \\
\hline
\end{tabular}

Fifty-five Brock and 22 Laurier faculty members commented on Question 2. Social science and business faculty commented on the absence of a factor for journal "fit" (selecting journals to reach a specific target audience). Impact factor (IF) received a range of comments demonstrating the problem with this traditional metric. Humanists did not view it as relevant. Social scientists felt that IF was a problematic metric to use in isolation but noted their views on journal prestige would consider IF and quality of the editorial board. Business faculty noted the importance of professional external rankings of journals. Science faculty comments were the strongest voice for making publishing decisions on IF and the importance of it for research funding and student scholarships.

\section{Part 2: Knowledge of OA Journal Publishing}

For the purposes of this study, a fully OA journal was defined as "a journal which makes all of its content immediately available for free to its readers and for which readers do not pay any subscriptions or other fees to access any articles."

\section{Question 4: Have you published an article in an OA journal?}

Most faculty at both institutions (Brock, $58 \%, n=121$; Laurier, $55 \%, n=76$ ) reported no previous OA publishing experience or were uncertain (see Table 3).

\section{Table 3}

Respondents Who Have Published an Article in an OA Journal (Q4)

\begin{tabular}{|l|r|r|r|r|r|r|}
\hline & \multicolumn{2}{|c|}{ Yes } & \multicolumn{2}{c|}{ No } & \multicolumn{2}{c|}{ Don't Know } \\
\cline { 2 - 7 } & Brock & Laurier & Brock & \multicolumn{1}{c|}{ Laurier } & Brock & \multicolumn{1}{c|}{ Laurier } \\
\hline Arts \& Humanities & $55 \%$ & $29 \%$ & $40 \%$ & $61 \%$ & $7 \%$ & $11 \%$ \\
\hline Business & $25 \%$ & $25 \%$ & $64 \%$ & $75 \%$ & $11 \%$ & $0 \%$ \\
\hline $\begin{array}{l}\text { Science / Health } \\
\text { Science }\end{array}$ & $37 \%$ & $57 \%$ & $52 \%$ & $43 \%$ & $10 \%$ & $0 \%$ \\
\hline Social Science & $45 \%$ & $46 \%$ & $49 \%$ & $44 \%$ & $7 \%$ & $10 \%$ \\
\hline
\end{tabular}




\section{Question 5: Do you plan to pursue publication in an OA journal?}

Nearly half of the respondents (42\% at Brock and $48 \%$ at Laurier) indicated that they would pursue publication in an OA journal within the next five years. Business faculty were the least likely to do so, with only $11 \%$ of Brock and $25 \%$ of Laurier business respondents indicating such intentions.

A very small number of participants (13 at Brock and 9 at Laurier) reported they would "never" publish in an OA journal. A higher percentage of business faculty at both Brock (29\%) and Laurier (36\%) reported they "never" planned to pursue publication in an OA journal than in other disciplines (see Table 4).

\begin{tabular}{|l|r|r|r|r|r|r|r|r|r|r|r|r|r|r|}
\hline Table 4 \\
Plans to Pursue Publication in an OA Journal (Q5) \\
\hline & \multicolumn{2}{|c|}{ Within 5 Years } & \multicolumn{3}{|c|}{ Uncertain } & \multicolumn{5}{c|}{ Never } \\
\hline & \multicolumn{2}{|c|}{ Brock } & \multicolumn{1}{|c|}{ Laurier } & \multicolumn{2}{|c|}{ Brock } & \multicolumn{2}{c|}{ Laurier } & \multicolumn{2}{c|}{ Brock } & Laurier \\
\hline & $\mathrm{n}$ & $\%$ & $\mathrm{n}$ & $\%$ & & $\mathrm{n}$ & $\%$ & $\mathrm{n}$ & $\%$ & $\mathrm{n}$ & $\%$ & $\mathrm{n}$ & $\%$ \\
\hline $\begin{array}{l}\text { Arts \& } \\
\text { Humanities }\end{array}$ & 18 & $43 \%$ & 10 & $36 \%$ & 22 & $52 \%$ & 17 & $61 \%$ & 2 & $5 \%$ & 1 & $4 \%$ \\
\hline Business & 3 & $11 \%$ & 3 & $25 \%$ & & 17 & $61 \%$ & 4 & $36 \%$ & 8 & $29 \%$ & 4 & $36 \%$ \\
\hline $\begin{array}{l}\text { Science / } \\
\text { Health }\end{array}$ & 25 & $42 \%$ & 14 & $47 \%$ & 31 & $53 \%$ & 15 & $50 \%$ & 3 & $5 \%$ & 1 & $6 \%$ \\
\hline Science & & & & & & & & & & & & & \\
\hline Social Science & 40 & $54 \%$ & 31 & $60 \%$ & & 33 & $45 \%$ & 18 & $35 \%$ & 0 & $0 \%$ & 3 & $7 \%$ \\
\hline
\end{tabular}

Fifty-five comments were received from Brock faculty and 16 from Laurier faculty for Question 5. The majority of comments were negative, expressing concerns about OA journals' low prestige and quality, potentially negative implications for tenure and promotion, poor past experiences with the OA publication process, and costs as a significant deterrent to publishing in an OA journal.

The positive comments indicated that participants might consider OA publication if OA became more prevalent and there was help with any associated costs. Faculty who had previously published in OA journals noted the benefits of increased exposure and article view metrics.

\section{Question 6: OA journals have the following characteristics...}

In Question 6, participants were offered a list of potential characteristics of OA journals and asked whether they "always", "often", "sometimes", or "never" had a characteristic. The respondent could also answer "I don't know." Responses for three specific characteristics-"peer reviewed" (see Table 5), "increase the "likelihood of being cited" (see Table 6) and "can count toward tenure/promotion" (see Table 7)-are reported because they align with results from other studies. 


\begin{tabular}{|l|l|l|r|r|r|r|r|r|}
\hline Table 5 \\
OA Journals Are Peer Reviewed (Q6a) \\
\hline
\end{tabular}

\section{Table 6}

OA Journals Increase the Likelihood of Being Cited (Q6e)

\begin{tabular}{|c|c|c|c|c|c|c|c|c|c|c|}
\hline \multicolumn{6}{|l|}{ 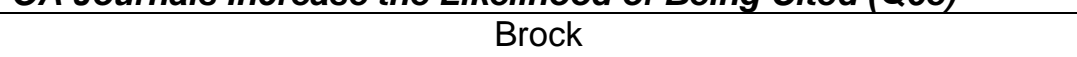 } & \multicolumn{5}{|c|}{ Laurier } \\
\hline & Always & $\begin{array}{l}\text { Often or } \\
\text { Sometimes }\end{array}$ & Never & $\begin{array}{l}\text { Don't } \\
\text { Know }\end{array}$ & $\begin{array}{c}\text { Total } \\
\text { Responses }\end{array}$ & Always & $\begin{array}{l}\text { Often or } \\
\text { Sometimes }\end{array}$ & Never & $\begin{array}{l}\text { Don't } \\
\text { Know }\end{array}$ & $\begin{array}{c}\text { Total } \\
\text { Responses }\end{array}$ \\
\hline $\begin{array}{l}\text { Arts \& } \\
\text { Humanities }\end{array}$ & $8 \%$ & $34 \%$ & $11 \%$ & $47 \%$ & 38 & $0 \%$ & $71 \%$ & $4 \%$ & $25 \%$ & 28 \\
\hline Business & $8 \%$ & $38 \%$ & $19 \%$ & $35 \%$ & 26 & $0 \%$ & $50 \%$ & $8 \%$ & $42 \%$ & 12 \\
\hline $\begin{array}{l}\text { Science / } \\
\text { Health } \\
\text { Science }\end{array}$ & $5 \%$ & $49 \%$ & $7 \%$ & $39 \%$ & 59 & $13 \%$ & $47 \%$ & $3 \%$ & $37 \%$ & 30 \\
\hline $\begin{array}{l}\text { Social } \\
\text { Science }\end{array}$ & $4 \%$ & $60 \%$ & $0 \%$ & $36 \%$ & 70 & $8 \%$ & $59 \%$ & $4 \%$ & $29 \%$ & 51 \\
\hline
\end{tabular}

Table 7

OA Journals Can Count Toward Tenure/Promotion (Q6g)

\begin{tabular}{|l|r|r|r|r|r|r|r|r|r|r|}
\hline \multicolumn{9}{|c|}{ Brock } & \multicolumn{6}{c|}{ Laurier } \\
\hline & Always & $\begin{array}{c}\text { Often or } \\
\text { Sometimes }\end{array}$ & Never & $\begin{array}{r}\text { Don't } \\
\text { Know }\end{array}$ & $\begin{array}{c}\text { Total } \\
\text { Responses }\end{array}$ & Always & $\begin{array}{c}\text { Often or } \\
\text { Sometimes }\end{array}$ & Never & $\begin{array}{r}\text { Don't } \\
\text { Know }\end{array}$ & $\begin{array}{c}\text { Total } \\
\text { Responses }\end{array}$ \\
\hline $\begin{array}{l}\text { Arts \& } \\
\text { Humanities }\end{array}$ & $23 \%$ & $38 \%$ & $5 \%$ & $35 \%$ & 40 & $18 \%$ & $43 \%$ & $11 \%$ & $29 \%$ & 28 \\
\hline Business & $0 \%$ & $43 \%$ & $21 \%$ & $36 \%$ & 28 & $0 \%$ & $58 \%$ & $17 \%$ & $25 \%$ & 12 \\
\hline $\begin{array}{l}\text { Science / } \\
\text { Health } \\
\text { Science }\end{array}$ & $25 \%$ & $36 \%$ & $2 \%$ & $37 \%$ & 59 & $37 \%$ & $43 \%$ & $0 \%$ & $20 \%$ & 30 \\
\hline $\begin{array}{l}\text { Social } \\
\text { Science }\end{array}$ & $25 \%$ & $57 \%$ & $0 \%$ & $18 \%$ & 72 & $18 \%$ & $51 \%$ & $2 \%$ & $29 \%$ & \\
\hline
\end{tabular}




\section{Part 3: Attitudes Toward OA}

\section{Question 8: These questions explore your attitudes towards OA}

Overall, most respondents were positive about making their research freely available to all readers (see Table 8).

\begin{tabular}{|c|c|c|c|c|}
\hline \multicolumn{5}{|c|}{$\begin{array}{l}\text { Table } 8 \\
\text { Respondents Who “Strongly Agree" or "Agree" with the Statement: } \\
\text { "My research should be freely available to all readers" (Q8a) }\end{array}$} \\
\hline & \multicolumn{2}{|c|}{ Brock } & \multicolumn{2}{|c|}{ Laurier } \\
\hline & $\mathrm{n}$ & $\%$ & $\mathrm{n}$ & $\%$ \\
\hline Arts \& Humanities & 42 & $76 \%$ & 28 & $82 \%$ \\
\hline Business & 28 & $57 \%$ & 11 & $64 \%$ \\
\hline Science / Health Science & 58 & $84 \%$ & 30 & $77 \%$ \\
\hline Social Science & 69 & $93 \%$ & 52 & $87 \%$ \\
\hline
\end{tabular}

Arts and humanities as well as social science respondents were more positive about OA journals as an important research dissemination strategy than business and science/health science respondents (see Table 9).

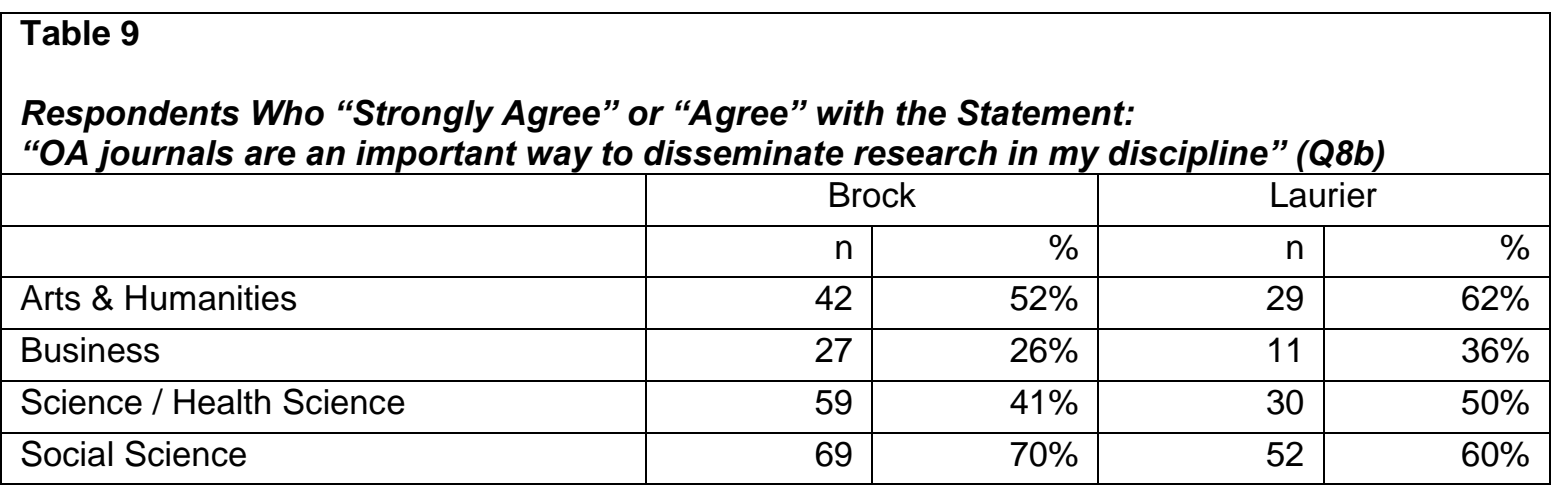

In terms of OA journals broadening research impact, business respondents were the least positive while social scientists the most positive (see Table 10).

\begin{tabular}{l} 
Table 10 \\
Respondents Who "Strongly Agree" or "Agree" with the Statement: \\
"Publishing in OA Journals broadens the impact of my research" (Q8C) \\
\hline \\
\hline
\end{tabular}


Most faculty respondents at both institutions did not want to spend their grant funds on open access publishing fees (see Table 11).

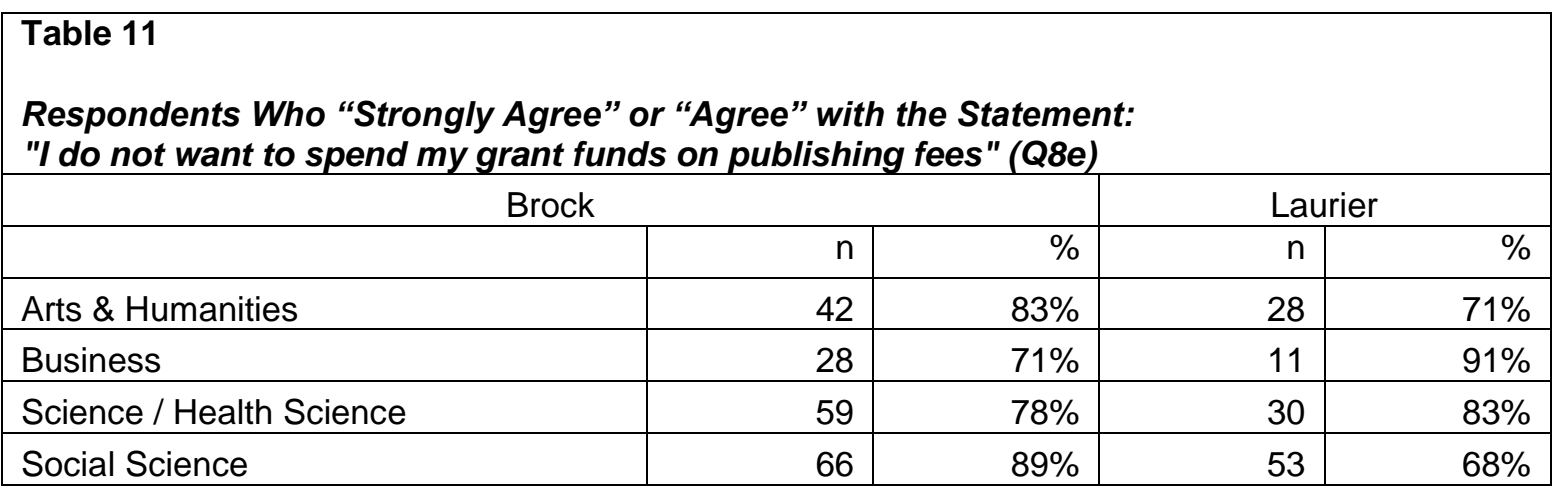

Twenty-five percent of faculty agreed that current promotion and tenure standards discourage OA. Business faculty were the outliers, with approximately $50 \%$ of faculty (Brock 46\%, $n=13$, Laurier $50 \%, n=6$ ) agreeing that promotion and tenure standards discourage OA publishing (see Table 12).

\begin{tabular}{|c|c|c|c|c|}
\hline \multicolumn{5}{|c|}{$\begin{array}{l}\text { Table } 12 \\
\text { Respondents Who "Strongly Agree" or "Agree" with the Statement: } \\
\text { "My current tenure and promotion standards discourage me from making my publications } \\
\text { OA" (Q8f) }\end{array}$} \\
\hline & \multicolumn{2}{|c|}{ Brock } & \multicolumn{2}{|c|}{ Laurier } \\
\hline & $\mathrm{n}$ & $\%$ & $\mathrm{~N}$ & $\%$ \\
\hline Arts \& Humanities & 41 & $12 \%$ & 28 & $25 \%$ \\
\hline Business & 28 & $46 \%$ & 12 & $50 \%$ \\
\hline Science / Health Science & 56 & $7 \%$ & 29 & $21 \%$ \\
\hline Social Science & 68 & $21 \%$ & 52 & $21 \%$ \\
\hline Total & 193 & & 121 & \\
\hline
\end{tabular}

Comments received for Question 8 raised concerns about OA journal quality, cost, and recognition in promotion and tenure. For example, a health sciences professor at Brock University remarked: "[t]here is a debate in my field regarding the ranking (value) of peer reviewed open access journals vs traditional peer reviewed journals. Therefore, with respect to tenure and promotion, depending on the review committee, some publications may not be recognized and "acceptable and credible" if a fee was paid to publish the article-i.e., that the publication was 'bought' not 'earned'."

\section{Question 9: OA journals are of higher, similar, or lower quality than subscription/pay-per-view journals.}

Brock's 199 responses revealed a lower view of the quality of OA journals in comparison to the 132 responses received from Laurier faculty. Only $45 \%$ of Brock faculty $(n=90)$ indicated that OA and subscription journals were of similar or higher quality to subscription journals, compared to $56 \%$ at Laurier $(n=74)$. The most 
notable negative responses were from business faculty, where over $85 \%$ of respondents felt OA journals were of lower quality. In the social sciences, $60 \%$ of faculty at both institutions viewed $O A$ as similar or higher quality to subscription journals (see Tables 13 and 14).

\section{Table 13}

OA Journals Compared with Subscription/Pay-Per-View Journals (Brock Q9)

\begin{tabular}{|c|c|c|c|}
\hline & Higher Quality & Similar Quality & Lower Quality \\
\hline & $\begin{array}{l}\% \text { of Total } \\
\text { Responses }\end{array}$ & $\begin{array}{l}\text { \% of Total } \\
\text { Responses }\end{array}$ & $\%$ of Total Responses \\
\hline Arts \& Humanities & $3 \%$ & $49 \%$ & $49 \%$ \\
\hline Business & $0 \%$ & $15 \%$ & $85 \%$ \\
\hline Science / Health Science & $0 \%$ & $36 \%$ & $64 \%$ \\
\hline Social Science & $0 \%$ & $62 \%$ & $38 \%$ \\
\hline
\end{tabular}

\begin{tabular}{|c|c|c|c|}
\hline \multicolumn{4}{|l|}{ Table 14} \\
\hline & Higher Quality & Similar Quality & Lower Quality \\
\hline & $\begin{array}{c}\text { \% of Total } \\
\text { Responses }\end{array}$ & $\begin{array}{c}\text { \% of Total } \\
\text { Responses }\end{array}$ & $\%$ of Total Responses \\
\hline Arts \& Humanities & $0 \%$ & $40 \%$ & $60 \%$ \\
\hline Business & $0 \%$ & $92 \%$ & $8 \%$ \\
\hline Science / Health Science & $0 \%$ & $50 \%$ & $50 \%$ \\
\hline Social Science & $2 \%$ & $37 \%$ & $61 \%$ \\
\hline
\end{tabular}

\section{Part 4: Profile of Survey Respondents}

\begin{tabular}{|l|r|r|r|r|}
\hline Table 15 \\
Completed Survey Responses by Broad Subject Area (Q11) \\
\hline & \multicolumn{2}{|c|}{ Brock $(n=208)$} & \multicolumn{2}{|c|}{ Laurier $(n=138)$} \\
\hline & $\mathrm{n}$ & $\%$ & $\mathrm{n}$ & $\%$ \\
\hline Arts \& Humanities & 42 & $20 \%$ & 28 & $20 \%$ \\
\hline Business & 28 & $13 \%$ & 12 & $8 \%$ \\
\hline Science \& Health Science & 59 & $28 \%$ & 30 & $22 \%$ \\
\hline Social Science & 69 & $33 \%$ & 52 & $37 \%$ \\
\hline Not answered & 10 & $5 \%$ & 16 & $11 \%$ \\
\hline
\end{tabular}

\section{Discussion}

\section{Publishing Practices}

Faculty at each institution had similar publishing histories: $66 \%(n=136)$ of Brock faculty had published from zero to 20 articles, compared to $69 \%(n=95)$ at Laurier. The 
institutions also had a similar number of faculty who had published more than 30 articles in their career (22\% at Brock and $24 \%$ at Laurier).

\section{Peer Review, Journal Prestige, Impact Factor most Important Factors in Choosing a Journal}

This study's results are like others in demonstrating that researchers submit articles to journals based on "traditional" standards. Per the Phase 5 Research Study, Canadian scientists choose a publication venue according to journal reputation and impact factor (Phase 5 Consulting, 2014). Studies at University of Toronto, University of Saskatchewan, and York University found, rather than whether a journal is available via $\mathrm{OA}$, that the embedded traditions of peer review, journal reputation, and journal relevance to the manuscript were key criteria faculty members used in determining a journal's suitability for publishing their article (Moore, 2011; Dawson, 2014; Nariani \& Fernandez, 2012). This too is true at Brock and Laurier, where, like at the University of Toronto, "conventional practices...continue to dominate" (Moore, 2011, p. 15).

The percentage of respondents ( $41 \%$ at Brock and $51 \%$ at Laurier) that ranked peer review as the most important criterion for selecting a journal in which to publish may understate its true importance to participants. In the comments section for this question, nine participants from Brock and three from Laurier commented that peer review is assumed and therefore not worth rating. In addition, the interrelatedness of peer review to other factors was noted-for instance, while promotion/tenure ranked low, comments indicated the tight relationship of this category to peer review. Several faculty noted that publishing in peer-reviewed journals was key to consideration of those articles in promotion and tenure.

\section{Knowledge of OA Journal Publishing}

Most business faculty members had not published in an OA journal. On the other hand, over $50 \%$ of Brock's humanists and Laurier's science faculty responded that they had previously published via OA. (see Table 3 ).

When asked whether they would consider publishing in an OA journal, Brock and Laurier faculty responded similarly, with fewer than $50 \%$ of respondents (Brock, $42 \%, n=85$; Laurier, $49 \%, n=67$ ) indicating they would consider publishing in an OA publication at some point. Only $6 \%$ of faculty at both institutions responded that they would never consider publishing in an OA journal. Notably, many respondents were "uncertain" (Brock, 52\%, $n=106$; Laurier, 45\%, $n=61$ ). The most positive responses for future OA publication plans came from the social science faculty, while business faculty expressed the least interest.

The survey also revealed some uncertainty regarding the characteristics of OA journals. Only $45 \%(n=19)$ of Brock humanists responded "always" to the statement "OA journals are always free to read". In contrast, $77 \%(n=23)$ of Laurier scientists responded "always" to the same statement. 
Comments made it clear that many faculty are struggling with the concept of $O A$ and how to differentiate it from subscription publishing. As one Brock scientist put it: "[t]o be honest, even after you defined what OA is, I'm still not sure if some of the journals in which I've published are OA." Several commenters referred to "print" versus "online" journals, further muddying the waters.

Some themes were repeated by a number of participants. For example, many respondents mentioned predatory publishers or described predatory publisher behaviour. An analysis by Crawford (2014) shows that predatory publishers as defined by Beall's List (2014) comprise fewer than $10 \%$ of the listings in the DOAJ. This presents an obvious opportunity for education of faculty and other potential OA authors. Another commonly stated view is that OA journal publishing is very expensive for authors. However, this again presents an opportunity for education, given that data shows two thirds of the journals in the DOAJ did not charge a fee (DOAJ, 2015).

Answers to Question 6 (OA Journals have the following characteristics...) reflected minor differences between the two institutions, with Brock participants indicating higher levels of uncertainty than Laurier participants (see Table 2). Uncertainty, though, was the major result from this question. Even characteristics we assumed would be common knowledge, for example, that OA journals are "always free to read", were met with uncertainty. Merely 115 of 200 Brock respondents (58\%) and 92 of 137 Laurier respondents (67\%) affirmed that OA Journals were "always free to read".

\section{The Value of Open Access}

Respondents were generally positive about the potential for OA journals to disseminate research. More than $75 \%$ of arts and humanities, science and health science, and social science faculty felt their research findings should be freely available to all readers. Less support was demonstrated by Brock and Laurier business faculty. While more than $60 \%$ of social science faculty members viewed $O A$ as important in either disseminating or broadening the impact of research, fewer than $30 \%$ of business faculty were of like mind. Overall, arts and humanities faculty were more positive than science and health science faculty regarding $\mathrm{OA}$ and research dissemination/impact.

This study confirmed what previous studies (e.g., Coonin, 2011; Coonin \& Younce, 2010; Harley, Acord, Earl-Novell, Lawrence \& King, 2010; Kozak \& Hartley, 2013; Lyons \& Booth, 2011; Moore, 2011) have noted: that disciplinary differences exist in attitudes to OA journal publishing, While arts and humanities, science and health science and social science participants conveyed a range of knowledge and attitudes about OA journal publishing, business faculty displayed a level of certainty and negativity that stood out. Business researchers were most likely to feel that they would never publish in an $O A$ journal, that current tenure and promotion guidelines discouraged publication in OA journals, and were almost unanimous in their belief that $O A$ journals were of lower quality than subscription journals. Interestingly, several business researchers commented that a key factor in choosing a publication venue was a journal's standing on an external ranking of business journals (Financial Times, 2012). If further 
investigation demonstrated that all business faculty value these rankings and that none of the ranked journals are OA, this might explain how business faculty responded to this survey.

One clear theme is the endurance of disciplinary culture and publishing traditions that influence tenure, funding decisions and other career rewards. Broad access to scholarship-one of the OA benefits heavily promoted by librarians-is not one of the things that matter most to faculty. As noted by Eve and Willinsky (2015), "academics will not, overnight, submit to new journals and new publishers unless the underlying incentives (usually financial for their institution and their own careers, mediated through prestige) also change" (pp. 88-89). Librarians may find more success reaching faculty by highlighting the IF of an OA journal, or demonstrating how a particular OA publication could be a good "fit" for an author's work. Librarians must be able to address issues vital to researchers: prestige, impact, and participating in relevant scholarly conversations.

In response to the question about the quality of $O A$ journals the most frequent comment ("it depends") highlighted the complexity of the current scholarly publishing landscape. There were lengthy thoughtful comments in the 60 Brock and 39 Laurier general comments (Question 10), about the current scholarly dissemination environment. Concerns about predatory OA journals and cost were mentioned, but most comments expressed positive visions for the future:

"Open-access journals are variable - undoubtedly some of the variation will wash out eventually, but currently it is a bit like the wild west out there." (Brock scientist)

"I think that open access publishing is extremely important today, due to globalization and interdisciplinary/international research this means of publication bring researchers and collaborative research closer". (Brock humanist)

"We have the responsibility to make the product of our publicly funded research available to those who paid for it (Canadians) as well as those who can use it." (Laurier social scientist)

\section{Conclusion}

The survey provided a significant amount of useful information on a wide range of topics which can help us, as librarians, to communicate more effectively with researchers about scholarly publishing. While most survey respondents at both institutions agreed that publicly available research is generally a good thing, this study has clearly identified obstacles which prevent faculty's positive attitudes towards OA from translating into open publishing practices.

The results of this exploratory study demonstrate that Brock and Laurier faculty members share common characteristics in both their publishing practices and attitudes towards OA. Science and health science researchers were the most positive about OA 
journal publishing; arts and humanities along with social sciences respondents were more mixed; and business participants were the least positive. These findings, in addition to specific researcher concerns about $O A$ (particularly cost and quality), provide evidence to inform institutional $O A$ educational efforts. Combining these insights about OA with the knowledge of key publishing factors for faculty-peer review, prestige, and impact factor-will allow librarians to address the priorities of researchers at their institutions.

Given the rapidly changing nature of OA scholarly publishing, characterized by one of our survey respondents and others as "a wild west", it is important to document faculty members' experiences by examining their changing behaviours and perceptions.

To effectively develop services to support publishing in gold OA journals, librarians should employ a variety of educational strategies (websites, seminars, consultations) to work with faculty members. By positioning ourselves as facilitators of effective research dissemination (rather than Tri-Agency compliance agents) librarians can facilitate conversations, tailored to disciplinary publishing practices to:

- encourage colleagues to judge the quality of a journal separately from its business model (OA, subscription, hybrid, APCs)

- demonstrate how OA journals can meet peer review and other quality standards

- directly address concerns and present realities about APCs and "predatory" journals

Canada's Tri-Agency OA Policy on Publications (Tri-Agency, 2015) provides impetus for these efforts: the policy encourages all Canadian researchers (regardless of funding) to make their research publicly accessible - a directive that brings Canada in line with other major nations including the U.K., the U.S., and Australia.

This study underscores the need for focused, open discussions on our campuses about the facts and fears surrounding OA journal publishing.

\section{Acknowledgements}

This study was supported by the Wilfrid Laurier University Research Support Fund. We wish to express our sincere thanks to our colleagues who participated in this study.

\section{References}

Beall, J. (2015). What the open access movement doesn't want you to know. Academe, 101(3), 37-40.

Beall, J. (2014, January 2). List of predatory publishers 2014. [web log post. Archived by Internet Archive Wayback Machine January 6, 2014]. 
Canadian Association of Learned Journals (2011). Scholarly journal publishing in Canada: Annual industry report (2010-11). Unpublished Report.

Canadian Association of Learned Journals (2015). CALJ response: Tri-Council's open access policy.

CARL Open Access Working Group. (2016, January). Library open access funds in Canada: review and recommendations.

Coonin, B. (2011). Open access publishing in business research: The authors' perspective. Journal of Business \& Finance Librarianship, 16, 193-212.

Coonin, B., \& Younce, L. M. (2010). Publishing in open access education journals: the authors' perspectives. Behavioral \& Social Sciences Librarian, 29(2), 118-132.

Crawford, W. (2014). Journals, 'journals' and wannabes: Investigating the list. Cites \& Insights 14(7), 1-24.

Dallmeier-Tiessen et al. (2011). Open access journals - what publishers offer, what researchers want. Information Services \& Use, 31, 85-91.

Dawson, D. D. (2014). Scholarly communication needs of faculty: An evidence based foundation for the development of library services. Evidence Based Library \& Information Practice, 9, 4-28.

Directory of Open Access Journals (2015). Historical APC data from before the April upgrade. DOAJ News Service.

Dowdy, B. (Presenter), Crotty, D. (Presenter), Bernhardt, B. (Presenter), Smith, P. H. (Presenter), \& Mayo, J. (Recorder) (2014). Challenges and opportunities of open access: A panel discussion. Serials Review, 40(3), 188-190.

Eve, M. P., \& Willinsky, J. (2015). Open access in humanities and social sciences: Visions for the future of publishing. College \& Research Libraries News, 76(2), 88-91.

Financial Times (2012). 45 Journals used in FT research rank. Financial Times.

Fowler, K. K. (2011). Mathematicians' views on current publishing issues: A survey of researchers. Issues in Science and Technology Librarianship, 67.

Frass, W., Cross, J. \& Gardner, V. (2014). Open access survey: Examining the changing views of Taylor \& Francis authors. Taylor \& Francis Group.

Harley, D., Acord, S. K., Earl-Novell, S., Lawrence, S., and King, C. J. (2010). Assessing the future landscape of scholarly communication: An exploration of 
faculty values and needs in seven disciplines. Center for Studies in Higher Education, UC Berkeley.

Kleinman, M. (2011). Faculty self-archiving attitudes and behavior at research universities: A literature review. Doctoral Seminar Paper. Center for the Study of Higher Education, University of Michigan.

Kozak, M., \& Hartley, J. (2013). Publication fees for open access journals: Different disciplines-different methods. Journal of the American Society for Information Science and Technology, 64(12), 2591-2594.

Lyons, C., \& Booth, H. A. (2011). An Overview of open access in the fields of business and management. Journal of Business \& Finance Librarianship, 16(2), 108-124.

Moore, G. (2011). Survey of University of Toronto faculty awareness, attitudes and practices regarding scholarly communication: A preliminary report.

Morrison, H. (2015, December 31). Dramatic growth of open access December 2015 [web log post].

Nariani, R., \& Fernandez, L. (2012). Open access publishing: What authors want. College and Research Libraries, 73(2), 182-195.

Natural Sciences and Engineering Research Council of Canada (2014). Opening Canadian research to the world: Summary of responses to draft Tri-Agency open access policy consultation. [web log post].

Open Science Initiative Working Group (2015). Mapping the future of scholarly publishing (1st ed.). Seattle: National Science Communication Institute.

Phase 5 Consulting (2014). Canadian researchers' publishing attitudes and behaviours: A Phase 5 report for Canadian Science Publishing.

Reinsfelder, T. L. (2012). Open access publishing practices in a complex environment: Conditions, barriers and bases of power. Journal of Librarianship and Scholarly Communication, 1(1): eP1029.

Social Sciences and Humanities Research Council (2004). Open Access Policy.

Steiginga, S. \& Evans, I. (2015, October 21). Finding open-access journals on Scopus keeps getting easier.

Suber, P. (2004). A very brief introduction to Open Access.

Togia, A., \& Korobili, S. (2014). Attitudes towards open access: A meta-synthesis of the empirical literature. Information Services \& Use, 34, 221-231. 
Partnership: The Canadian Journal of Library and Information Practice and Research, vol. 11, no. 2 (2016)

Tri-Agency (Canada). (2015). Tri-Agency open access policy on publications.

Wiley. (2012). What authors want from open access publishing.

Xia, J. (2010). A Longitudinal study of scholars attitudes and behaviors. Journal of the American Society for Information Science and Technology, 61(3), 615-624. 


\section{Appendix A}

\section{Part 1: Publishing practices}

\section{Survey instrument}

These questions address your experiences with and attitudes towards scholarly journal publishing.

1. How many articles have you published as primary author in scholarly journals over the span of your academic career?
a. $0-9$
b. $10-19$
c. $20-29$
d. $30+$

2. What factors influence your decisions on where to publish? Please select the four factors most important to you and rank in order of importance from 1 (most important) to 4 (least important): * Please choose ONLY 4 factors *

Impact factor Journal is peer reviewed

My work is more likely to be cited if published here Journal prestige within my discipline Impact on my promotion/tenure process

Articles in the journal are available to the general public Speed of review process Quality of editor/editorial board

Comments:

3. When you sign an agreement to publish your work in a journal, do you usually: (please select all that apply)

a. read the copyright terms in the publishing contract thoroughly before signing

b. sign the publishing contract without reading the copyright terms

c. negotiate with the publisher to change the contract and preserve more author rights over your article (for example, for you to post on a website)

d. negotiate with the publisher to change the contract and preserve more reader rights over your article (for example, for readers to share it widely online)

Comments: 


\section{Part 2: Knowledge of OA journal publishing}

For the purposes of this study, a fully $O A$ journal is defined as a journal which makes all of its content immediately available for free to its readers. Readers do not pay any subscriptions or other fees to access any articles in an OA journal.

4. Have you published an article in an OA journal?
a. Yes
b. No
c. Don't know

5. Do you plan to pursue publication in an $O A$ journal within:
a. the next 6 months
b. the next 12 months
c. the next 1 to 5 years
d. never
e. uncertain

Comments:

6. OA journals have the following characteristics:

\begin{tabular}{|l|l|l|l|l|l|}
\hline & Always & Often & Sometimes & Never & $\begin{array}{r}\text { I don't } \\
\text { know }\end{array}$ \\
\hline $\begin{array}{l}\text { a. } \begin{array}{l}\text { are peer } \\
\text { reviewed }\end{array} \\
\text { b. } \begin{array}{l}\text { charge fees } \\
\text { for authors to } \\
\text { publish in } \\
\text { them }\end{array}\end{array}$ & & & & & \\
\hline $\begin{array}{l}\text { c. } \begin{array}{l}\text { are free to } \\
\text { anyone to } \\
\text { read }\end{array} \\
\text { d. } \begin{array}{l}\text { have an } \\
\text { impact factor }\end{array}\end{array}$ & & & & & \\
\hline e. $\begin{array}{l}\text { increase the } \\
\text { likelihood of } \\
\text { being cited }\end{array}$ & & & & & \\
\hline f. $\begin{array}{l}\text { increase the } \\
\text { exposure of } \\
\text { your research } \\
\text { because } \\
\text { articles can }\end{array}$ & & & & & \\
\hline
\end{tabular}




\begin{tabular}{|l|l|l|l|l|l|}
\hline $\begin{array}{l}\text { be read by } \\
\text { anyone }\end{array}$ & & & & & \\
\hline g. $\begin{array}{l}\text { can count } \\
\text { towards } \\
\text { tenure / } \\
\text { promotion }\end{array}$ & & & & & \\
\hline h. $\begin{array}{l}\text { allow author } \\
\text { more ability } \\
\text { to reuse/post } \\
\text { content } \\
\text { without } \\
\text { restrictions }\end{array}$ & & & & & \\
\hline $\begin{array}{l}\text { allow } \\
\text { copyright to } \\
\text { reside with } \\
\text { the author }\end{array}$ & & & & & \\
\hline
\end{tabular}

7. Hybrid journals are subscription journals that offer an option to authors to make their individual articles $O A$ for a fee. Other articles in the journal issue are not freely available and can only be read by subscribers. For example, see Taylor \& Francis Open Select journals.
a. I am aware of this option
b. I am somewhat aware of this option
c. I was not aware of this option

Comments:

\section{Part 3: Attitudes toward OA}

8. These questions explore your attitudes towards OA:

\begin{tabular}{|c|c|c|c|c|c|}
\hline & $\begin{array}{c}\text { Strongly } \\
\text { Agree }\end{array}$ & Agree & Neutral & Disagree & $\begin{array}{l}\text { Strongly } \\
\text { Disagree }\end{array}$ \\
\hline $\begin{array}{l}\text { a. My research should be } \\
\text { freely available to all } \\
\text { readers }\end{array}$ & & & & & \\
\hline $\begin{array}{l}\text { b. OA journals are an } \\
\text { important way to } \\
\text { disseminate research in } \\
\text { my discipline }\end{array}$ & & & & & \\
\hline c. Publishing in $\mathrm{OA}$ journals & & & & & \\
\hline
\end{tabular}




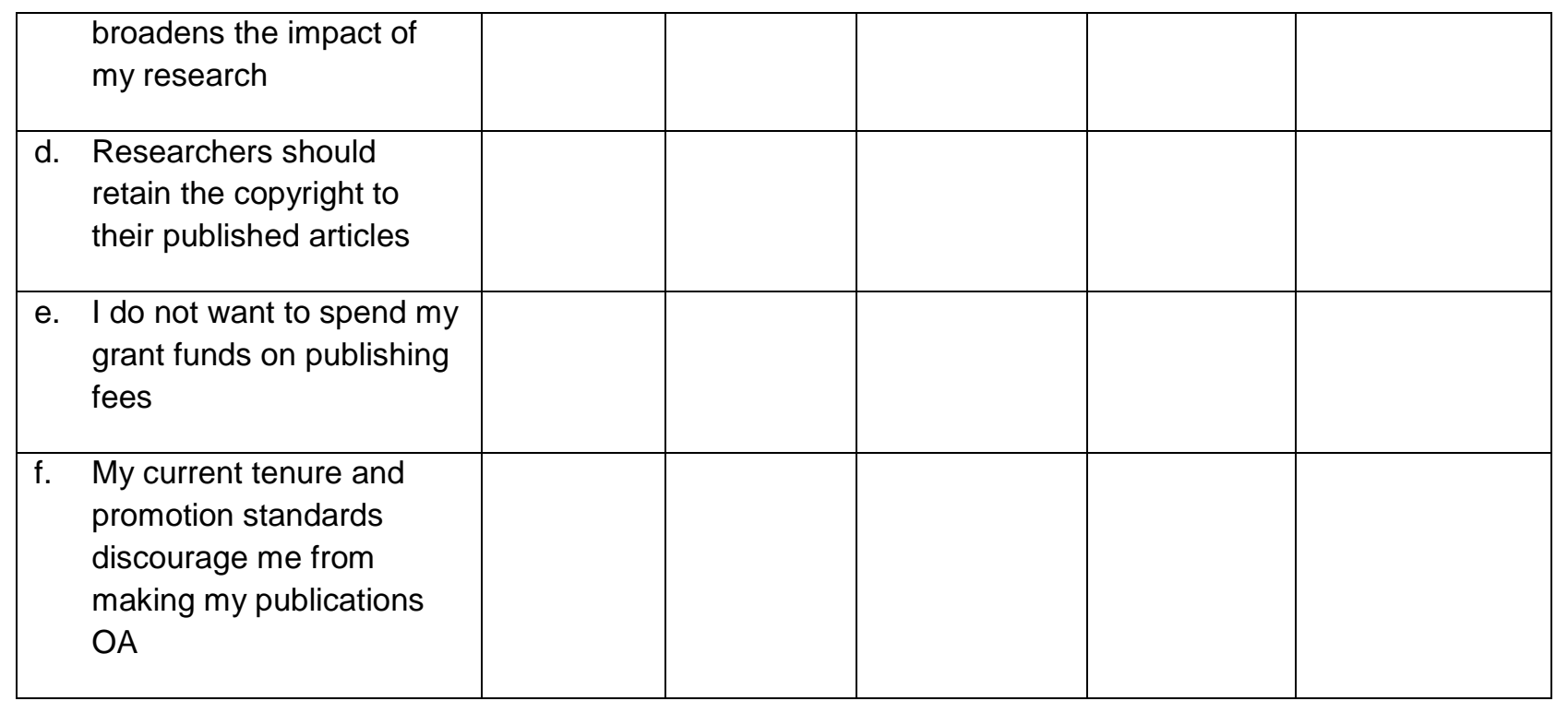

Comments:

9. OA journals are (select one which best matches your opinion):

a. of higher quality than subscription/pay-per-view journals

b. of similar quality to subscription/pay-per-view journals

c. of lower quality than subscription/pay-per-view journals

Comments:

10. Do you have any final comments or concluding thoughts about the topic of $O A$ publishing?

\section{Part 4: Demographics}

These last questions will help us better understand the relationship between researcher characteristics such as discipline and rank and your publishing practices and attitudes.

11. What is your home department?

\section{Applied Health Sciences}

Community Health Sciences

Kinesiology

Nursing

Recreation \& Leisure Studies

Sport Management

\section{Business}

Accounting

Finance, Operations, and Information Systems

Marketing, International Business, and Strategy 
Organizational Behaviour, Human Resources, Entrepreneurship, and Ethics

\section{Education}

Adult Education

Graduate \& Undergraduate Studies in Education

Teacher Education

Tecumseh Centre for Aboriginal Research and Education

\section{Humanities}

Applied Linguistics

Canadian Studies

Centre for Digital Humanities

Centre for Medieval and Renaissance Studies

Classics

Dramatic Arts

English Language \& Literature

History

Intercultural Studies

Liberal Arts

Modern Languages / Literatures \& Cultures

Music

Philosophy

Visual Arts

\section{Mathematics and Science}

Biological Sciences

Biotechnology

Chemistry

Computer Science

Earth Sciences

Mathematics \& Statistics

Physics

\section{Social Sciences}

Applied Disability Studies/ABA

Child \& Youth Studies

Communication, Popular Culture \& Film

Economics

Geography

Labour Studies

Political Science

Psychology

Social Justice and Equity Studies

Sociology

Tourism and Environment 


\section{Women's and Gender Studies}

\section{Other:}

11. What is your age?
a. $25-34$
b. $35-44$
c. $45-54$
d. $55-64$
e. $65+$

12. What is your gender?
a. Male
b. Female
c. Other

13.\# years since completing highest degree?
a. $0-5$
b. $6-10$
c. 11-15
d. $16-20$
e. $20-25$
f. $25+$

14. What is your rank?
a. Assistant Professor
b. Associate Professor
c. Full Professor
d. Lecturer
e. LTA Contract Faculty
f. Professor Emeritus
g. Other-please specify

EXIT

Thank you for participating in this research project. 